\title{
Competitive and noncompetitive rearing and shock-elicited aggression in the rat
}

\author{
ROBERT ADER \\ Department of Psychiatry, University of Rochester School of Medicine and Dentistry, Rochester, New York 14642
}

\begin{abstract}
Beginning at 21 days of age, rats were housed 10 per cage in a competitive environment (a large cage containing a single food and water source) or a noncompetitive environment (a large cage containing multiple food and water sources). At maturity, matched pairs of animals from within a single rearing cage were tested for shock-elicited fighting over five 100-trial sessions. In each of two experiments, animals reared in the noncompetitive environment displayed more aggressive behavior than animals reared in the competitive environment.
\end{abstract}

Studies of agonistic behavior in several species have indicated that the prior social history of the organism is an important determinant of aggressive behavior. Even in the shock-elicited fighting paradigm (Ulrich \& Azrin, 1962), in which the aggressive behavior is considered to be reflexive, previous social interactions still exert an influence on the incidence of aggression (Hutchinson, Ulrich, \& Azrin, 1965). Differences in methodology, however, preclude any generalizations concerning the nature of this influence.

Hutchinson et al. (1965) observed less shockelicited fighting behavior during a single test session among rats reared individually than among animals that were reared in communal cages. Hutzell and Knutson (1972) also observed less fighting among animals housed individually than among animals housed 7.8 per cage. Thor and Ghiselli (1974) noted less fighting among individually housed rats than among group housed animals (4/cage) on the first of several test sessions, but the individually caged animals displayed the greater incidence of aggression thereafter. Similarly, Creer and Powell (1971) reported more shock-elicited aggressive behavior in individually caged rats than in animals caged in pairs.

There is a vast literature on the effects of population size on physiological function and behavior (including agonistic behavior), but, again, differences in species, strain, sex, density, duration of experience, and conceptualizations (e.g., what constitutes a "crowded" social environment) obviate any definitive conclusions regarding the nature of the effects of social organization on agonistic behavior. Variations in population size or density necessarily impose corresponding variations in the nature of the social organization that ensues. It may be supposed, for example, that increasing population density while holding the available food and water sources constant increases competitive contacts between members of a group. Interestingly, it is usually stated that the animals used in an experiment on population size were provided with food and water ad lib, but the

This research was supported by The Grant Foundation, Inc.. and by USPHS Grants MH-23533 and K5-MH-6318 from the National Institute of Mental Health. The technical assistance of Darbbie Mahany is gratefully acknowledged. number of food and water sources is rarely, if ever, specified. As a potential source of the variability between group housed populations and as a factor contributing to subsequent aggressive behavior, then, the present study examined the effect of varying the competitive aspects of a social environment while holding population density constant.

\section{METHOD}

\section{Experiment I}

Pregnant Charles River (CD) rats were received from the supplier and delivered and reared their litters in standard plastic cages containing nesting materials. The animals were maintained under a standard 12-h light-dark cycle and provided with food and water ad lib. At weaning (21 days) the rats were weighed, ear tagged, and randomly placed into groups of 10 in stainless steel monkey cages $(59 \times 61 \times 55 \mathrm{~cm})$ containing a $1.25 \mathrm{~cm}$ wire mesh floor. One group of males and one group of females were randomly designated as the "competitive" group and were provided with a single food hopper and a single water bottle. A second sample of males and females comprised the "noncompetitive" group and was supplied with 8 food hoppers and 8 drinking bottles per cage.

Animals were weighed again at 42,60 , and 90 days of age. At approximately 60 and 90 days of age the consumption of water was measured daily over a period of 4 days.

Beginning at 92 days of age, animals were tested for shock-licited aggressive behavior. Weight-matched pairs of rats from the same cage were placed within a $45.7 \mathrm{~cm}$ Lucite cylinder with an inside diameter of $21.6 \mathrm{~cm}$. The cylinder stood on the stainless steel grid floor of a shock chamber that had three black walls and one clear plastic side. This apparatus was located within an Industrial Acoustic soundproofed experimental cubicle. Animals were permitted to explore the chamber for $1 \mathrm{~min}$ before testing began (and observations within this period revealed no spontaneous fighting behavior). Automatic programming equipment provided 20.5 -sec electric shocks per min. Scrambled electric shock $(1.5 \mathrm{~mA})$ was delivered by a Lehigh Valley (113-3) solid state shocker. Animals received 100 trials per day over 5 successive days. Pairs of animals were treated as statistical units and the number of trials on which fighting occurred (an upright, face-to-face posture, "boxing," and/or biting) was registered on a counter operated by a remote switch. Throughout the period of testing the animals remained in their respective rearing environments.

\section{Experiment II}

In an attempt to obtain periodic observations of behavior within the competitive and noncompetitive environments, the 
Table 1

Mean ( \pm SE) Total Daily Water Intake Per 10 Animals Reared in Competitive and Noncompetitive Environments

\begin{tabular}{|c|c|c|c|}
\hline & Group & 60 Days & 90 Days \\
\hline Males & $\begin{array}{l}\text { Competitive } \\
\text { Noncompetitive }\end{array}$ & $\begin{array}{l}450.8 \pm 11.9 \\
499.5 \pm 5.5\end{array}$ & $\begin{array}{l}572.8 \pm 12.1 \\
544.2 \pm 24.3\end{array}$ \\
\hline Females & $\begin{array}{l}\text { Competitive } \\
\text { Noncompetitive }\end{array}$ & $\begin{array}{l}292.0 \pm 5.6 \\
345.0 \pm 9.3\end{array}$ & $\begin{array}{l}351.0 \pm 15.5 \\
427.8 \pm 37.6\end{array}$ \\
\hline
\end{tabular}

front wall of two of the monkey cages was replaced with a Lucite panel. Such observations are not being reported here because the dye used for the identification of individual animals proved unsuitable for reliable videotape recording. This procedural modification, however, required that the number of food and water sources available in the noncompetitive environment be reduced to five. Also, no measures of water consumption were made in this experiment. In all other respects, the procedures of Experiment II were identical to those of Experiment I.

The shockelicited fighting behavior of one pair of noncompetitive females was eliminated from the analysis of the data, since one animal was able to leap to the top of the cylinder and hang there on four of the five trials.

\section{RESULTS}

\section{Body weight}

Animals reared in the competitive and noncompetitive environments showed a comparable growth over the first three months of life. There was some suggestion that noncompetitive males weighed more than competitive males by 90 days of age, but this difference was significant only in Experiment II $(t=2.18, p<.05)$.

\section{Water consumption}

The daily consumption of water by animals in Experiment $I$ is shown in Table 1 . These mean values reflect the total intake of the 10 animals housed in each cage over the 5 days on which measurements were made. At 60 days of age the water consumption of the animals housed in the noncompetitive environment was greater than that of animals housed in the competitive environment $(t=3.71$ and $4.88, p<.01$ for males and females respectively). At 90 days of age, the time at which aggressive behavior was measured, there were no significant differences in the water consumption of the two groups.

\section{Aggressive behavior}

The incidence of shockelicited fighting in Experiments I and II is shown in Figure 1. A single analysis of the total number of fights yielded only the significant main effect for group; animals reared and maintained in a noncompetitive environment showed more shock-elicited fighting behavior than animals housed in a competitive environment $(F=15.23$, df $=1 / 36, p<.01$ ).

It was recently reported (Creer, 1974) that when rats are housed six per cage and subsequently paired for testing in the shockelicited aggression situation, only one of the three pairs from each cage exhibited a high incidence of fighting; the other pairs displayed relatively low, variable instances of aggressive behavior. In order to verify this observation, the total number of fights displayed by individual pairs within each of the competitive and noncompetitive cages was examined. These data are shown in Figure 2. Almost all the pairs of noncompetitive animals responded to the shock with fighting behavior, whereas only one, or at most two, of the pairs from any given competitive environment displayed a high incidence of shockelicited aggression.

\section{DISCUSSION}

One of the consequences of differential housing is a modification of agonistic behaviors. The relation between population size or density and subsequent aggressive behavior is not at all clear. Under certain circumstances and in certain species, increases in population size can result in increases or decreases in aggressive encounters. Increases in population size, however, accomplish more than increasing the number of animals living in a given space or increasing the number of possible physical contacts between animals. In addition to altering the nature of the environment (e.g., ambient temperature), changes in population size result in changes in the nature of the social interaction among individual members of the group. The purpose of the present study was to examine one feature of the social interaction among animals, namely competition, while holding constant other environmental factors, primarily population density. Given a constant population size of 10 animals, those reared in an environment containing a single source of food and water were defined as being in a "competitive"

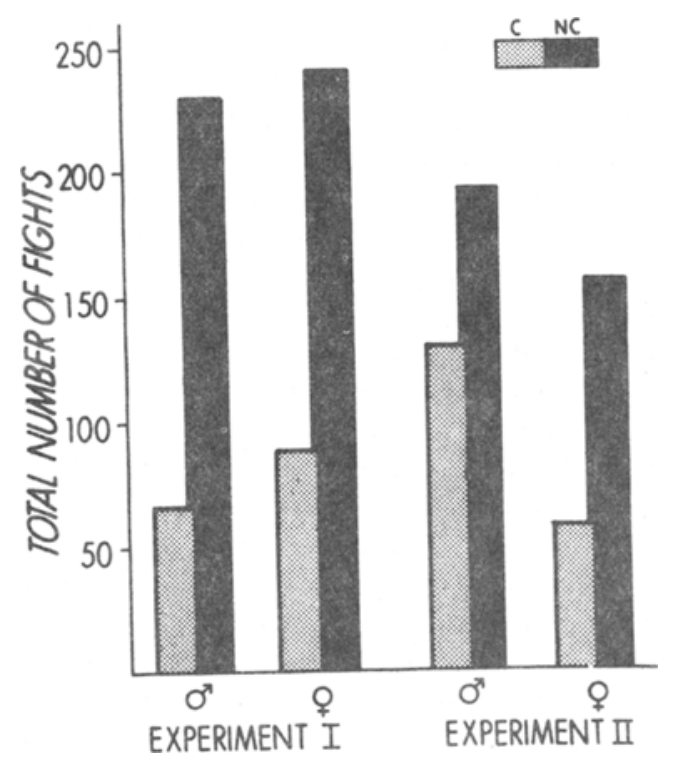

Figure 1. Mean number of shockelicited fights by pairs of rats reared in competitive (C) and noncompetitive (NC) environments. 
environment, while those that had access to multiple food and water sources were defined as being in a "noncompetitive" environment. The manipulation of this single variable, the number of available sources of food and water, resulted in significant differences in aggressive behavior. When subsequently tested for shock-elicited fighting behavior, animals reared in the noncompetitive environment consistently displayed more aggressive behavior than animals reared in the competitive environment.

As a post hoc explanation of these findings, it is hypothesized that the differences in aggressive behavior resulted from differences in the degree to which a stable dominance hierarchy had been established in the competitive and noncompetitive cages. It is assumed that the environment containing the single source of food and water would have increased the likelihood of physical contact between animals in the group, and that the nature of this physical contact reflected, to some extent, a competition for the single source of food or water. Conversely, the availability of multiple sources of food and water would have decreased the necessity for competitive encounters in order to satisfy these needs. If the greater incidence of competitive contacts facilitated the establishment of a stable dominance hierarchy, such animals might be less likely to assume an attack posture or engage in actual fights with members of that same population in response to a nonspecific painful stimulus. Such an hypothesis is consistent with observations that aggressiveness is minimal in populations in which a stable dominance order has evolved (e.g., Gottier, 1972). Because the test situation elicited a reflexive type of fighting behavior and occurred outside the environment to which the animals were accustomed, the present results would seem to increase the generalizability of these previous observations.

The data obtained in this study do not provide for any experimental verification of this hypothesis. An initial attempt to obtain videotape samples of behavior in these rearing environments was unsuccessful. However, the data obtained on the incidence of fighting between individual pairs of animals (Figure 2) are of some relevance. Of the five pairs of rats derived from each competitive cage of 10 animals, only one pair (two pairs in one instance) showed a high incidence of shock-elicited fighting. These results are consistent with the observations reported by Creer (1974) and reinforce the notion that the competitive environment created in the present experiment most closely approximates the conditions under which rats are usually caged in such studies of the effects of population size. In contrast, the reverse was true for animals reared in the noncompetitive environment; almost all pairs showed a high incidence of aggressive behavior. One interpretation of this difference is that it, too, reflects the existence of
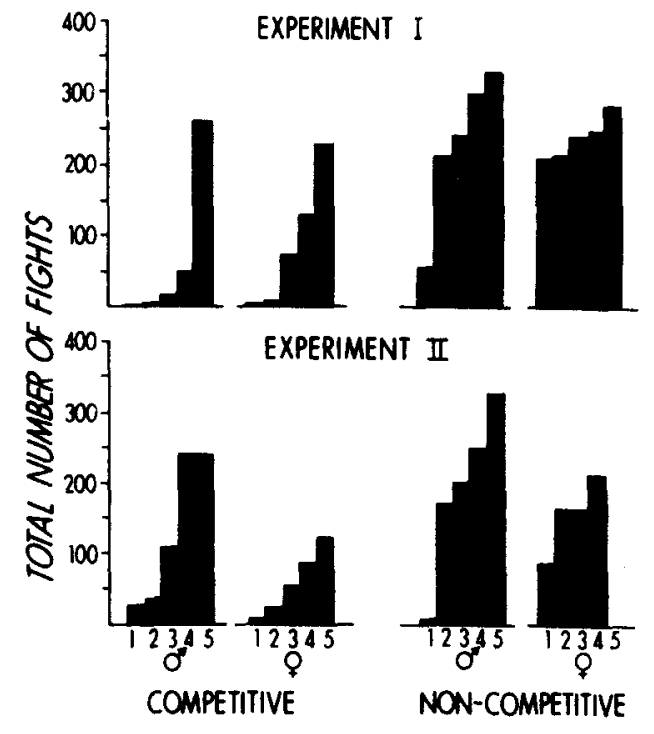

PAIRS OF ANIMALS

Figure 2. Total number of shockelicited fights displyyed by individual pairs of male and female rats reared in competitive and noncompetitive environments.

a relatively stable dominance hierarchy among animals reared in a competitive environment. It remains to be determined, however, if the results obtained in the present experiments can be attributed simply to an increased frequency of physical contact among group housed animals, or, as hypothesized, is a function of the competitive nature of such physical contact. Also, the precise relationship between competition and population size in determining subsequent aggressive behavior has yet to be defined.

\section{REFERENCES}

Creer, T. L. Communal houging and shock-induced agereasion. Bulletin of the Psychonomic Society, 1974, 4, 51-53.

Creer, T. L., Powell, D. A. Effects of age and housing conditions on shocktinduced aggression. Psychonomic Science, 1971, 22, 269-261.

Gottier, R. F. Factors affecting agonistic behavior in several subhuman species. Genetic Psychology Monographs, 1972, 86, 177-218.

Hutchinson, R. R., Ulrich, R. E., Azrin, N. H. Effects of age and related factors on the pain-aggression reaction. Joumal of Comparative and Physiological Psychology, 1865, 59. 365-369.

Hutzell, R. R., \& Knutson, J. F. A comparison of shock-licited fighting and shockelicited biting in rats. Physiology and Behavior, 1972, 8, 477-480.

Thor, D. H., \& Ghiselli, W. B. Visual and social determinants of shockelicited aggressive responding in rats. Animal Learning \& Behavior, 1974, 2, 74-76.

Ulich, R., \& Azrin, N. H. Reflexive fighting in response to aversive stimulation. Joumal of the Experimental Analysis of Behavior, 1962, 5, 511-520.

(Received for publication February 18, 1975. Revision accepted May 5, 1975.) 